\title{
ПРИМЕНЕНИЕ БЕСПИЛОТНЫХ АВИАЦИОННЫХ СИСТЕМ В КАДАСТРОВОЙ ДЕЯТЕЛЬНОСТИ
}

\author{
Александр Александрович Антонов \\ Сибирский государственный университет геосистем и технологий, 630108, Россия, г. Ново- \\ сибирск, ул. Плахотного, 10, обучающийся, тел. (983)314-37-59, \\ e-mail: al.antonov98@gmail.com
}

\section{Дмитрий Владимирович Гоголев}

Сибирский государственный университет геосистем и технологий, 630108, Россия, г. Новосибирск, ул. Плахотного, 10, аспирант, тел. (962)840-47-40, e-mail: GogolevDV96@mail.ru

\section{Владислав Александрович Зазулин}

Сибирский государственный университет геосистем и технологий, 630108, Россия, г. Новосибирск, ул. Плахотного, 10, обучающийся, тел. (913)769-96-31, e-mail: zazulinvlad97@gmail.com

В статье представлено применение современных программных и технических средств, дается определение и перспективы развития фотограмметрического метода в кадастровой деятельности, а также возможности применения беспилотных летательных аппаратов

Ключевые слова: беспилотные авиационные системы, фотограмметрический метод, беспилотный летательный аппарат.

\section{APPLICATION OF UNMANNED AERIAL SYSTEMS IN CADASTRAL ACTIVITIES}

\section{Alexandr A. Antonov}

Siberian State University of Geosystems and Technologies, 10, Plakhotnogo St., Novosibirsk, 630108, Russia, Student, phone: (983)314-37-59, e-mail: al.antonov98@gmail.com

\section{Dmitry V. Gogolev}

Siberian State University of Geosystems and Technologies, 10, Plakhotnogo St., Novosibirsk, 630108, Russia, Ph. D. Student, phone: (962)840-47-40, e-mail: GogolevDV96@mail.ru

\section{Vladislav A. Zazulin}

Siberian State University of Geosystems and Technologies, 10, Plakhotnogo St., Novosibirsk, 630108, Russia, Student, phone: (913)769-96-31, e-mail: zazulinvlad97@gmail.com

The article presents use of modern software and hardware, gives definition and prospects for the development of the photogrammetric method in cadastral activities, as well as the possibility of using unmanned aerial vehicles

Keywords: unmanned aerial systems, photogrammetric method, unmanned aerial vehicle

Современный уровень развития технологий, программного обеспечения, информатизации и цифровизации позволяют представить окружающий мир в формате 3D (3D-моделирование). Одной из сфер, для которых наиболее востребовано развитие данного направления, является сфера земельно-имущественных отношений (СЗИО), которая характеризуется интенсивным гражданским оборотом, 
а также высокой кадастровой стоимостью объектов недвижимости. В результате анализа международного опыта по внедрению 3D-моделирования в кадастры, системы управления земельными ресурсами и градостроительное планирование территорий, являющихся составными частями СЗИО, а также в сферы строительства и архитектуры выявлено, что наиболее значительные успехи были достигнуты в строительстве (замена компьютерных (CAD) чертежей на динамические информационные (BIM) модели) и кадастре недвижимости (переход на 3D-кадастры) [1$3,11,12]$.

Рассмотрев структуру функционирующих 3D-кадастров недвижимости, можно отметить, что в большей степени такие системы ориентированы на описание и учет 3D-моделей зданий, сооружений и объектов незавершенного строительства, в меньшей - земельных участков $[5,11]$. В то же время, дискуссионным остается вопрос о необходимости 3D-моделирования внутренних помещений зданий и сооружений, а также способах визуализации таких моделей.

Существует несколько вариантов создания 3D-модели, но в работе со зданиями сложной конструкции рационально использовать фотограмметрический метод с применением БПЛА.

$\mathrm{B}$ процессе создания 3D-модели для кадастрового учета с использованием БПЛА выделяют основные этапы, представленные на рис. 1.

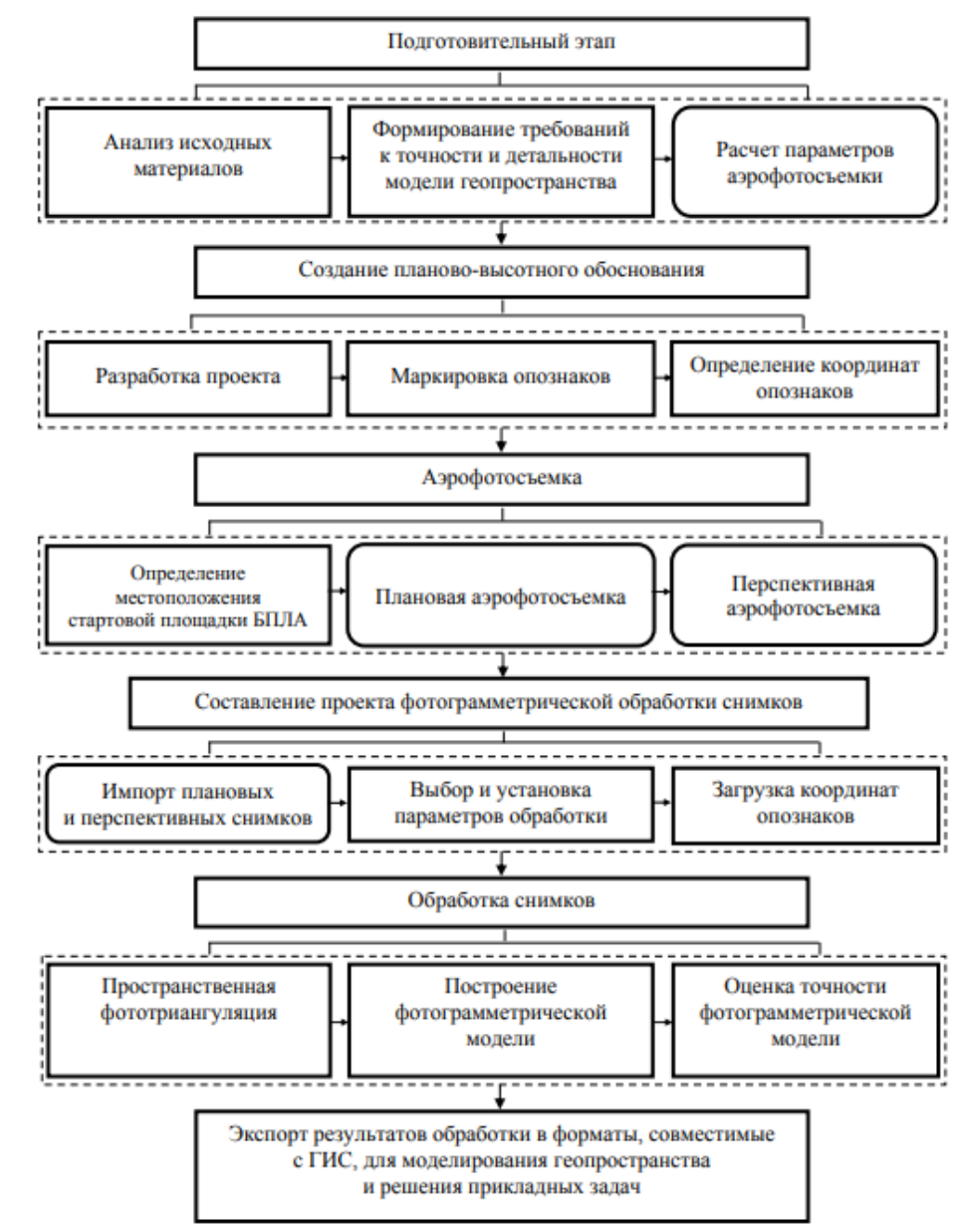

Рис. 1. Технологическая схема сбора и обработки данных АФС с использованием БПЛА для моделирования геопространства 
Планово-высотное обоснование представляет собой сеть координатных точек, закрепленных на местности временными знаками, часть из которых являются опорными, а часть контрольными.

После создания сети планово-высотного обоснования выполняется этап съемки объекта недвижимости БПЛА с камерой неметрического типа [28, 37]. Аэрофотосъемка выполняется в несколько маршрутов: съемка по периметру на высоте выше самого здания, съемка над крышей и съемка по контуру здания на уровне средних этажей.

Результат аэрофотосъемки обрабатывается в специализированном программном обеспечении. В ходе данного исследования обработка проводилась в программе Autodesk Recap для формирования облака точек моделируемого объекта. Параллельно выполнялся этап фототриангуляции, необходимый для координатной привязки $3 \mathrm{D}$-модели здания. После выполнения этих этапов создается пространственная модель здания с необходимыми данными для постановки на трехмерный кадастровый учет [14-16]. Пример приведен на рис. 2.

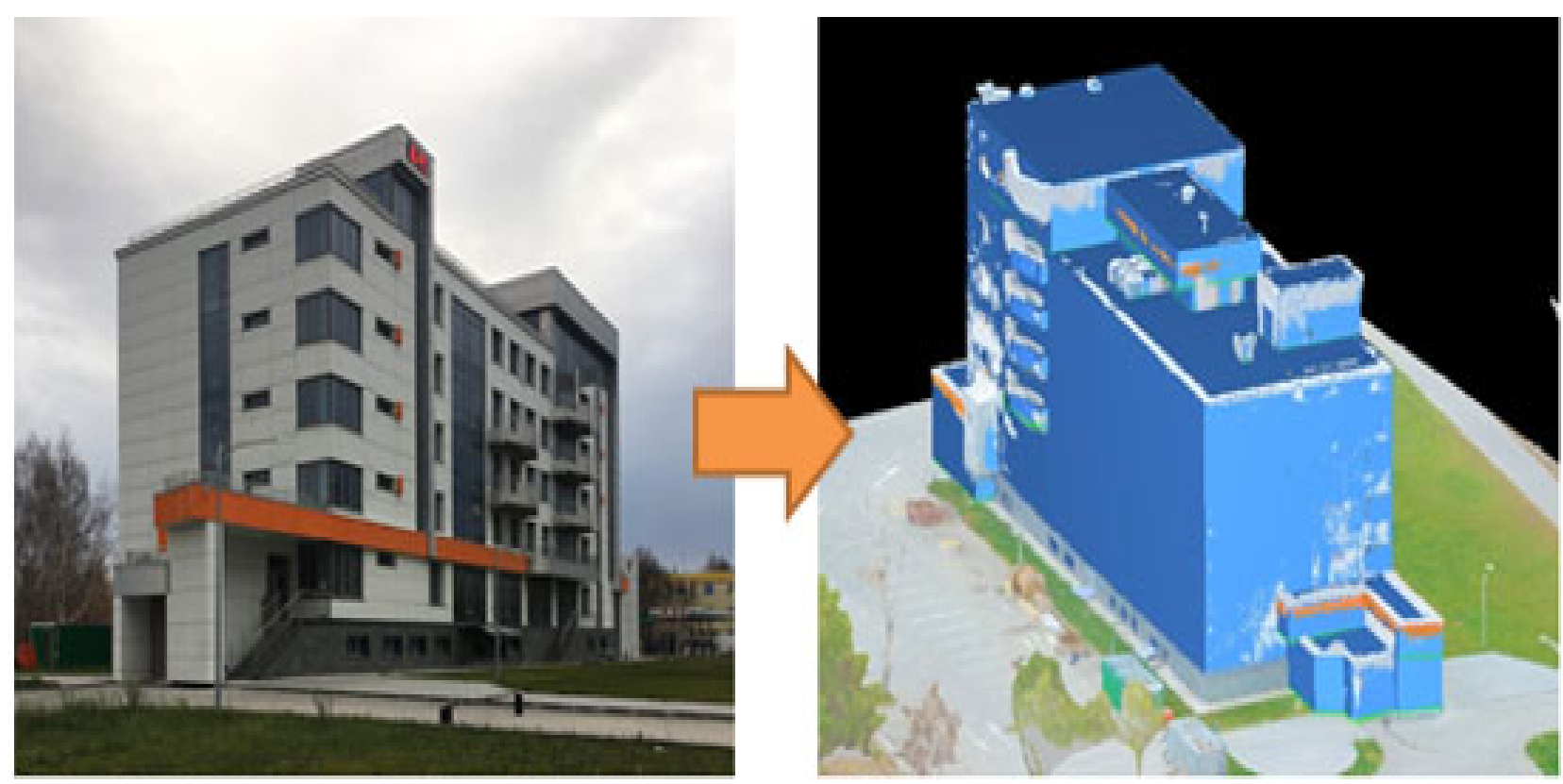

Рис. 2. Результаты этапов формирования 3D модели

Для корректной постановки 3D-модели на кадастровый учет, необходимо предоставить Росреестру данные модели в одном из форматов: DXF, RVT, PLN, SKP $[9,10]$.

Работа по формированию топографических планов выполняется по материалам аэрофотосъемки. Технологическая схема, применяемая при использовании БПЛА представлена на рис. 3. 


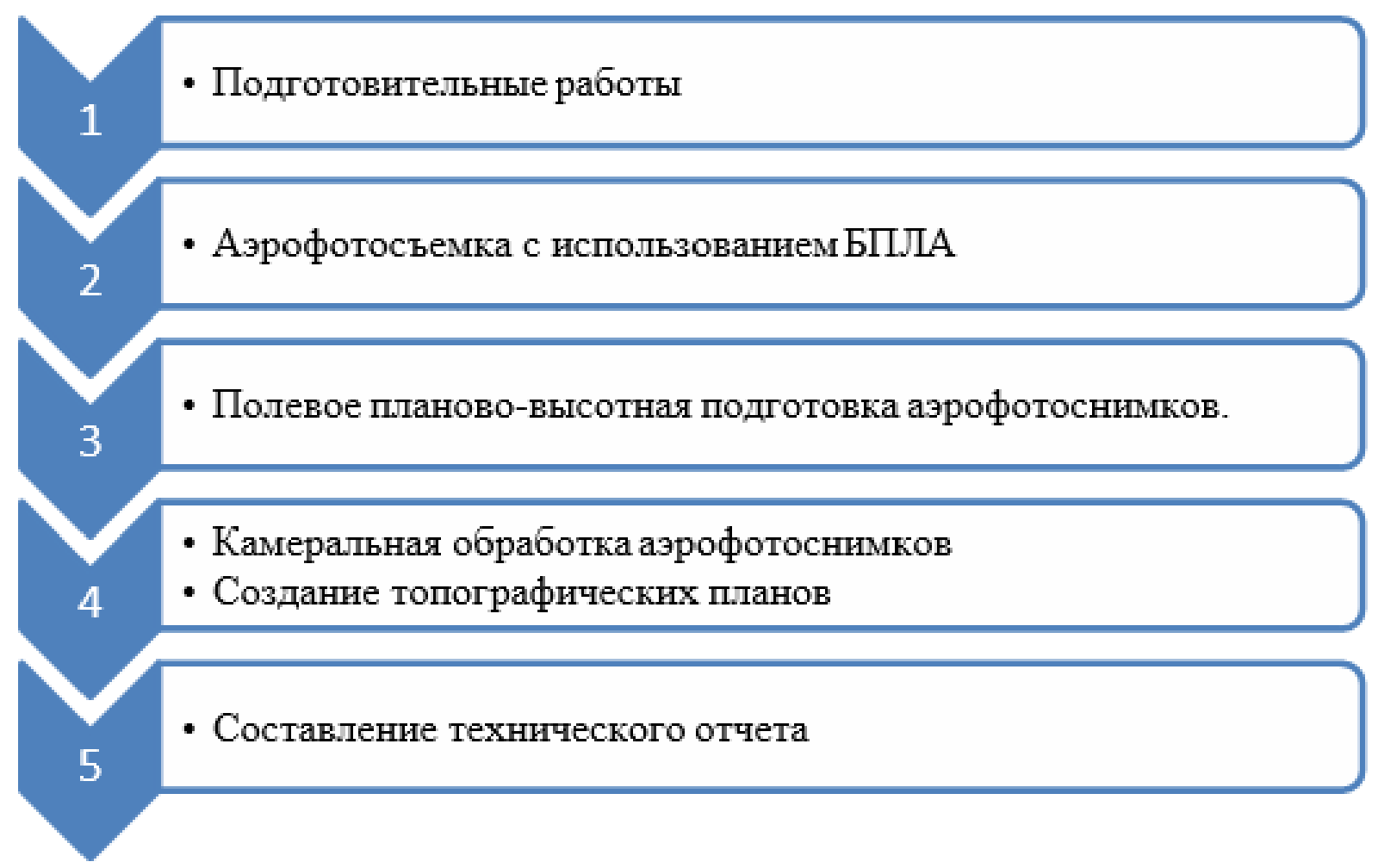

Рис. 3. Технологическая схема выполнения работ при создании цифровых топографических планов

Подготовительные этапы работы включают в себя:

- изучение исходных материалов; формирование или сбор требований к материалам, которые необходимо получить в результате выполнения АФС - тип карты и ее масштаб, границы объекта съемки; приведение их в технические требования к съемочным материалам: разрешение, координаты контура участка съемки, перекрытие снимков, точность определения координат центров фотографирования, требования к наземной опорной сети;

- построение полетного задания для БПЛА. Выполняется программой планировщиком полета, Pix 4D, DJI GO. Оператор должен выбрать используемый комплекс БПЛА (в случае, если программа позволяет работать с несколькими конфигурациями БПЛА и фотоаппаратуры), задать на карте контур участка съемки и примерное положение стартовой площадки, установить требуемое разрешение и перекрытие, после чего программа рассчитывает план полета и проверяет возможность его корректного выполнения [4, 11, $16]$.

АФС с использованием БПЛА. Съемка проводится с учетом конфигурации участка съемки и рассчитанных параметров. С помощью встроенного в БПЛА GPS-приемника определяются координаты начала и конца полета. Пример схемы маршрута БПЛА представлен на рис. 4. 


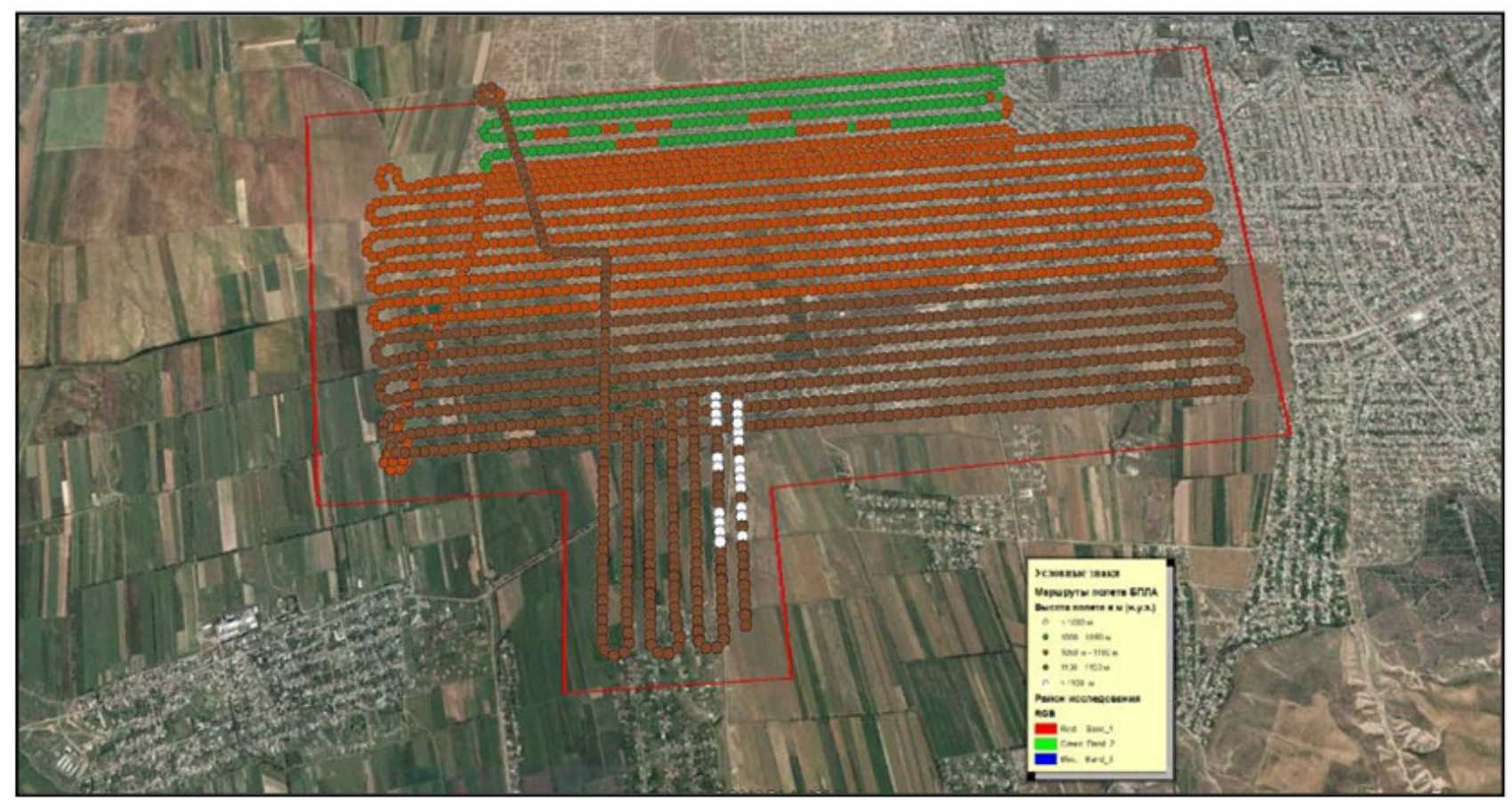

Рис. 4. Схема маршрутов полета БПЛА

По результатам формирования накидного монтажа, оцениваются следующие параметры:

- наличие некорректных снимков в маршруте (некорректным считается снимок, если одно из пересечений смежных снимков меньше заданного);

- отклонение масштаба снимков от заданного (не более 5 \%);

- продольное и поперечное перекрытие кадров;

- прямолинейность маршрутов $[4,6,12]$.

По результатам анализа накидного монтажа дополнительное проведение АФС не потребовалась (рис. 5).

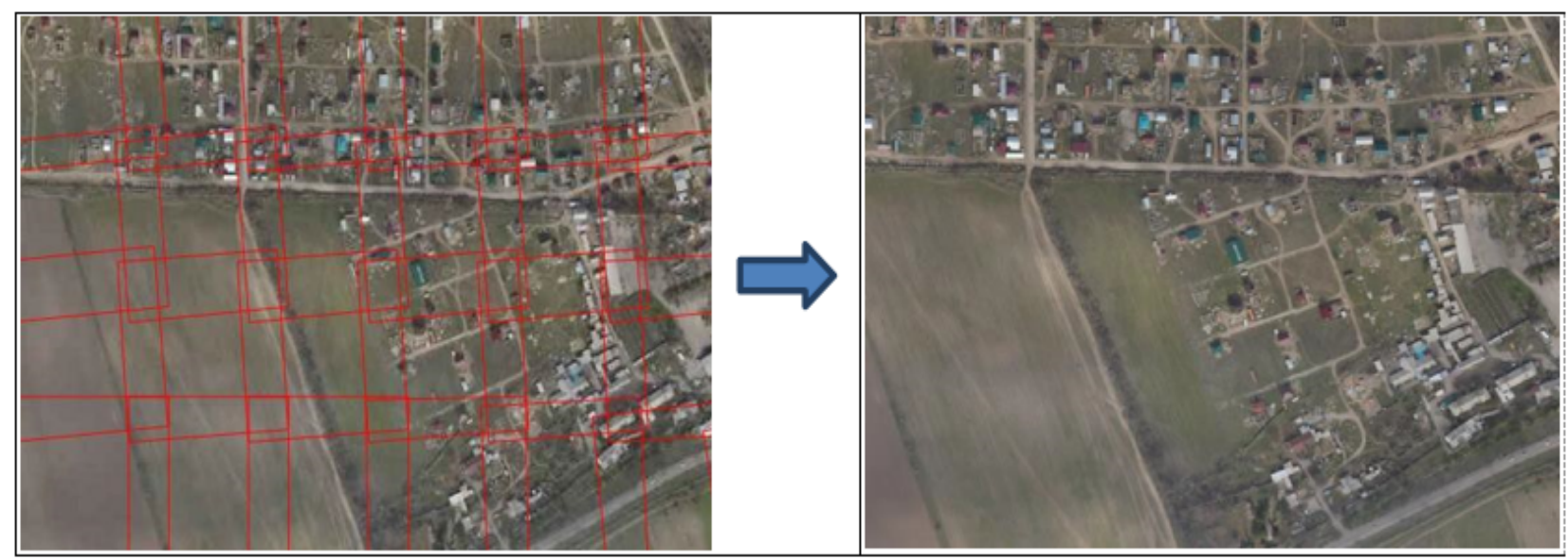

Рис. 5. Фрагмент репродукции накидного монтажа 
По результатам анализа накидного монтажа программой аэрофотосъемочных расчетов формируется отчет в виде формализованного документа, который вместе с материалами АФС прикладывается к акту выполненных работ для передачи в подразделение, осуществляющее фотограмметрические работы.

При входном контроле камеральной обработки подлежат проверке следующие требования:

- покрытие аэрофотоснимками территории съемки;

- соответствие материалов АФС требованиям нормативно-правовых и технических документов;

- качество изображения;

При наличии снимков с отклонениями по маршруту или угла наклона камеры в процессе фотографирования такие аэрофотоснимки исключаются из этапа дальнейшей обработки.

Этап камеральной обработки. Дешифрирование ортофотопланов производится одновременно с оцифровкой распознаваемых объектов на ортофотоплане камеральным способом. При дешифрировании как справочный материал можно использовать карты масштаба 1:25000 прошлых лет съемки (рис. 6).

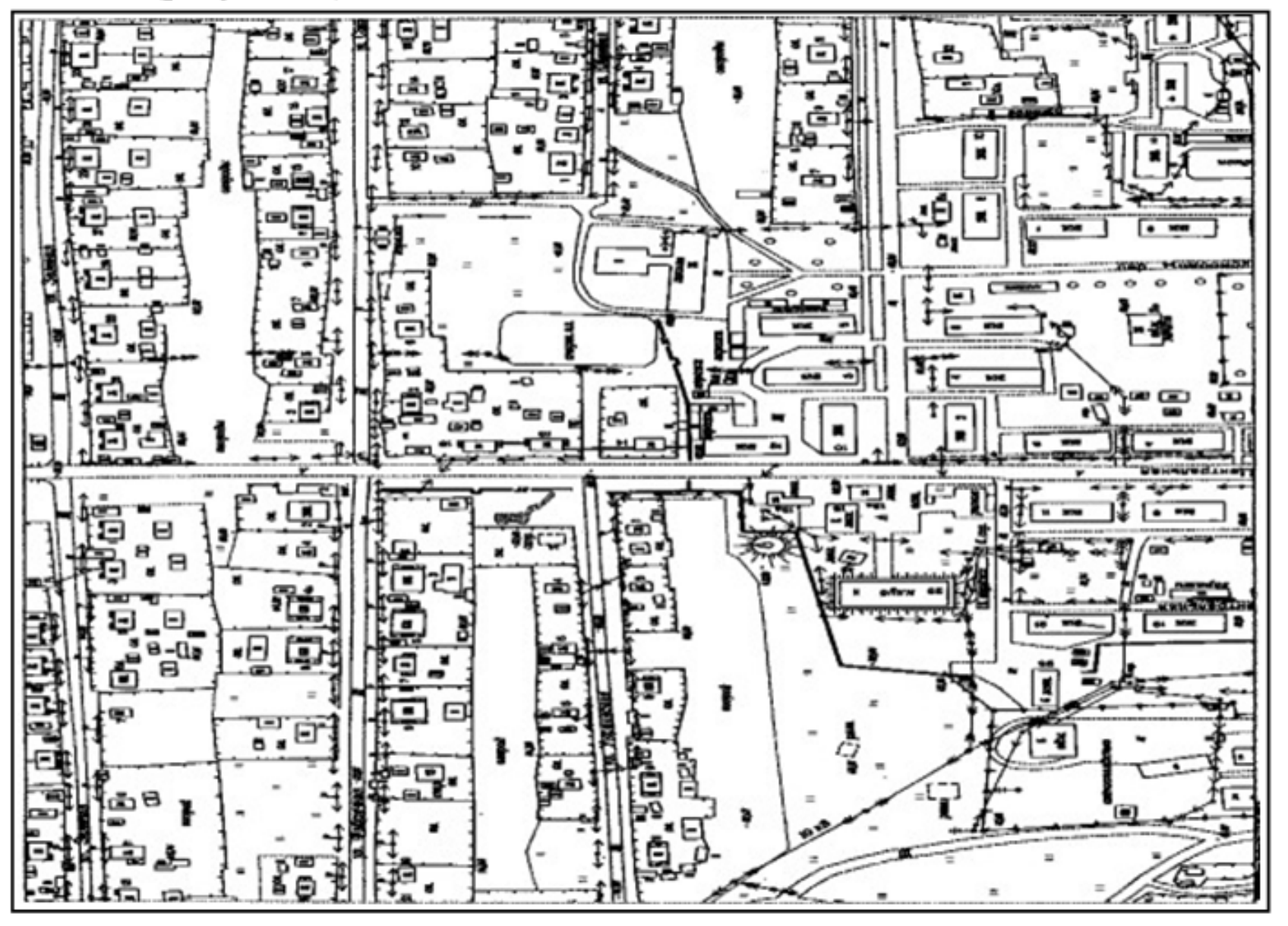

Рис. 6. Фрагмент плана на участок аэрофотосъемочных работ 
Подготовка технического отчета производится после проведения вышеуказанных работ, формируется отчет, отображающий следующие требования:

- сроки проведения, границы района работ;

- характеристики используемого оборудования;

- диапазон высот АФС;

- масштаб созданного цифрового топографического плана.

Опыт применения БПЛА для формирования цифровых топографических планов позволяет получать плотные массивы точек, объектов сложной формы. Такие модели обеспечивают точное измерение объемов, высот и перепадов рельефа, а также дают возможность формирования топографических планов высокой точности в камеральных условиях $[1,3,14]$.

\section{БИБЛИОГРАФИЧЕСКИЙ СПИСОК}

1. Алябьев, А. А. Фотограмметрический метод в кадастровых работах: цифровые стереомодели и ортофотопланы [Текст] / А. А. Алябьев, К. А. Литвинцев, Е. А. Кобзева // Геопрофи. -2018 . - № 2. - С. 4-8.

2. Антипов, И. Т. Об использовании цифровых средне- и малоформатных камер для аэрофотосьемки [Текст] / И. Т. Антипов, Е. А. Кобзева // Геодезия и картография. - 2013. № 11. - C. 29-34.

3. Арбузов, С. А. Реализация практико-ориентированного обучения посредством научно-образовательного и производственного центра беспилотных авиационных систем (НОПЦ БАС) СГУГиТ [Текст] / С. А. Арбузов, М. А. Петрова, О. А. Опритова // АКТУАЛЬНЫЕ ВОПРОСЫ ОБРАЗОВАНИЯ. Инновационные подходы в образовании. Междунар. науч.метод. конф. : сб. материалов в 2 ч. (Новосибирск, 23-27 января 2017 г.). - Новосибирск : СГУГиТ, 2017. Ч. 1. - С. 210-214.

4. Воздушный кодекс Российской ФедерацииФедерации [Электронный ресурс]: Федеральный закон от 19.03.1997 N 60-Ф3 // СПС «КонсультантПлюс».

5. Гебгарт, Я. И. Некоторые вопросы измерения снимков [Текст] / Я. И. Гебгарт, У. Д. Ниязгулов, А. А. Гебгарт // Геодезия и картография. - 2005. - № 2. - С. 24-25.

6. ГКИНП (ГНТА)-02-036-02. Инструкция по фотограмметрическим работам при создании цифровых топографических карт и планов [Текст]. - М. : ЦНИИГАиК, 2002. - 100 с.

7. ГКИНП-09-32-80. Основные положения по аэрофотосъемке, выполняемой для создания и обновления топографических карт и планов [Текст]. - М. : Недра, 1982. - 17 с.

8. ГКИНП 02-121-79. Руководство по дешифрированию аэроснимков планов масштабов $1: 2000$ и $1: 5000$ [Текст]. - М. : ЦНИИГАиК, $198 \mathrm{c.}$

9. Об утверждении требований к точности и методам определения координат характерных точек границ земельного участка, требований к точности и методам определения координат характерных точек контура здания, сооружения или объекта незавершенного строительства на земельном участке, а также требований к определению площади здания, сооружения и помещения : приказ Минэкономразвития России от 01.03.2016 № 90 [Электронный ресурс]. - Доступ из справ.- правовой системы «КонсультантПлюс».

10. "Об утверждении Федеральных правил использования воздушного пространства Российской Федерации" [Электронный ресурс]: Постановление Правительства РФ от 11.03.2010 N 138 (ред. от 03.02.2020) // СПС «КонсультантПлюс».

11. Опритова, О. А. Исследование возможностей применения беспилотных авиационных систем для моделирования объектов недвижимости [Текст] / О. А. Опритова // Вестник СГУГиТ. - 2018. - Т. 23, № 3. - С. 248-258.

12. Оценка точности 3D-моделей, построенных с использованием беспилотных авиационных систем [Текст] / Е. И. Аврунев, Х. К. Ямбаев, О. А. Опритова, А. В. Чернов, Д. В. Гоголев // Вестник СГУГиТ. - 2018. - Т. 23, № 3. - С. 211-228. 
13. Раков, Д. Н. Выбор цифрового неметрического фотоаппарата для беспилотного аэрофотосъемочного комплекса [Текст] / Д. Н. Раков, В. Н. Никитин // 85 Интерэкспо ГЕОСибирь-2012. VIII Междунар. науч. конгр. : сб. молодых ученых СГГА (Новосибирск, 10-20 апреля 2012 г.). - Новосибирск : СГГА, 2012. - С. 27-36.

14. Хлебникова, Т. А. Экспериментальные исследования точности построения фотограмметрической модели по материалам БПЛА [Текст] / Т. А. Хлебникова, О. А. Опритова, C. М. Аубакирова // Интерэкспо ГЕО-Сибирь. XIV Междунар. науч. конгр. : Междунар. науч. конф. «Дистанционные методы зондирования Земли и фотограмметрия, мониторинг окружающей среды, геоэкология» : сб. материалов в 2 т. (Новосибирск, 25-27 апреля 2018 г.). - Новосибирск : СГУГиТ, 2018. Т. 1. - С. 32-37.

15. Цветков, В. Я. Автоматизированные фотограмметрические методы восстановления архитектурных объектов [Текст] : дис. ... д-ра техн. наук : 05.24 .02 : защищена 18.11 .1994 / Цветков Владимир Яковлевич. - М., 1994. - 323 с.

16. Agisoft PhotoScan Professional Edition : руководство пользователя. Версия 1.2 [Электронный ресурс]. - Режим доступа : http://www.agisoft.com/pdf/ photoscan-pro_1_2_ru.pdf.

(C) А. А. Антонов, Д. В. Гоголев, В. А. Зазулин, 2021 